\title{
A New On-line Sample Preparation System for the Liquid Chromatography/Time-of-Flight Mass Spectrometry Simultaneous Analysis of Pesticides in River Water
}

\author{
Hideki SaSaKi, ${ }^{* \dagger}$ Jun YoneKubo,* and Kazuichi HaYaKaWA** \\ *Nihon Waters K. K., 3-12, Kitashinagawa 1-chome, Shinagawa, Tokyo 140-0001, Japan \\ **Graduate School of Natural Science and Engineering, Kanazawa University, \\ Kakuma-machi, Kanazawa 920-1192, Japan
}

\begin{abstract}
Current on-line solid-phase extraction methods combined with HPLC for shortening the clean-up operation are not suitable for simultaneously detecting compounds that have a wide variety of hydrophobicities. To solve these problems, we designed a new on-line sample preparation system. The system consists of an eluting pump, a mixing TEE connector, a 10-port 2-position valve and a solid-phase extraction precolumn. The eluate from the precolumn is diluted with a weak solvent from the HPLC at the TEE connection to load low hydrophobic compounds onto the analytical column. The proposed on-line sample preparation system was successfully applied to the simultaneous analysis of 21 pesticides in river water using LC/TOF-MS. In this method, the recoveries from river water samples were 67 to $126 \%$ (mean $83 \%$ ), the reproducibility $(\mathrm{CV} \%)$ was in the range from 1.1 to $11 \%$ (mean $5.6 \%$ ), the calibration curve was linear in the range from $1 \mathrm{ppb}$ to $500 \mathrm{ppb}(r>0.999)$ and the detection limits $(S / N=3)$ were in the range from $0.0034 \mathrm{ppb}$ (daimuron) to 3.3 ppb (oxine-copper).
\end{abstract}

(Received January 13, 2006; Accepted April 24, 2006)

\section{Introduction}

Liquid chromatography/mass spectrometry (LC/MS) is an analytical technique that is widely used for the determination of various kinds of environmental contaminants. ${ }^{1-7}$ Orthogonalacceleration time-of-flight mass spectrometry (oa-TOF MS) permits calculating the elemental composition of the chemical compounds for concentrations at the ppb level.,6,7

Generally, the use of highly selective LC/MS requires a shorter analysis time and simpler sample clean-up procedures. However, co-eluting species, such as salts, proteins, phospholipids, humic materials and sugars, have a strong effect on the ionization process, referred to as the matrix effect. As a result of the matrix effect, the reproducibility and recovery depend on the sample-preparation method. ${ }^{8-20}$

The matrix effect also alters the collision-induced dissociation (CID) spectra. ${ }^{2,16}$ In order to reliably identify and quantify compounds, special attention has to be paid to making the calibration curve $\mathrm{e}^{10,12,17,20}$ and to comparing the spectrum pattern. ${ }^{21,22}$ The matrix effect can be eliminated by sample preparation, such as diluting the sample, liquid-liquid extraction or solid-phase extraction (SPE). ${ }^{9}$ The procedures can be time consuming, laborious and expensive, and can reduce the sensitivity.

On-line SPE is one of the practical methods for shortening the clean-up operation. ${ }^{3,4,13,15,25-28}$ However, this approach is not suitable for simultaneously detecting compounds that have a wide variety of hydrophobicities, because at the front on the analytical column the sample zone of low hydrophobic

$\dagger$ To whom correspondence should be addressed.

E-mail: hideki_sasaki@waters.com compounds diffuse as a result of the large volume of the strong solvent that flows from the SPE cartridge.

In this report, we present a new automated sample-preparation system that has both at-column-dilution $(\mathrm{ACD})^{23,24}$ and on-lineSPE (SPE/ACD), in order to load a large volume of strong eluent onto the analytical column.

\section{Experimental}

Apparatus and reagents

The HPLC system was a Model 2695-chromatography manager (Waters, Milford, MA, USA) equipped with a $2 \mathrm{~mL}$ sample loop and a $2.5 \mathrm{~mL}$ syringe. The oa-TOF MS was a LCT-Premier (Waters) equipped with Z-spray electrospray (ESI) source and a Lock spray. The photodiode array (PDA) detector was a Model 2996 (Waters). Each module was controlled by MassLynx software v. 4.0 (Waters). The analytical column was an Atlantis dC18, $150 \times 4.6 \mathrm{~mm}$ i.d., 5 $\mu \mathrm{m}$ particles (Waters). The SPE precolumn was an Oasis HLB extraction column $20 \times 2.1 \mathrm{~mm}$ i.d., $30 \mu \mathrm{m}$ particle size (Waters). The 10-port 2-position valve was a Model EV700102-WA (Reodyne, Cotati, CA, USA). The 2695 pump module and the 10-port 2-position valve were electrically connected in order to control the valve. The time events of the valve were switch 1 On, sample preparation position, and switch 1 Off, analysis position. The isocratic (eluting) pump was a Reagent Manager (Waters).

Carbofuran, bensulide, carbaryl, diuron, methomyl, benfuracarb, MBC (carbendazim), oxine-copper, thiophanatemethyl, thiram, daimuron, bensulfuron-methyl, tricyclazole, halosulfuron-methyl, flazasulfuron, siduron were purchased 

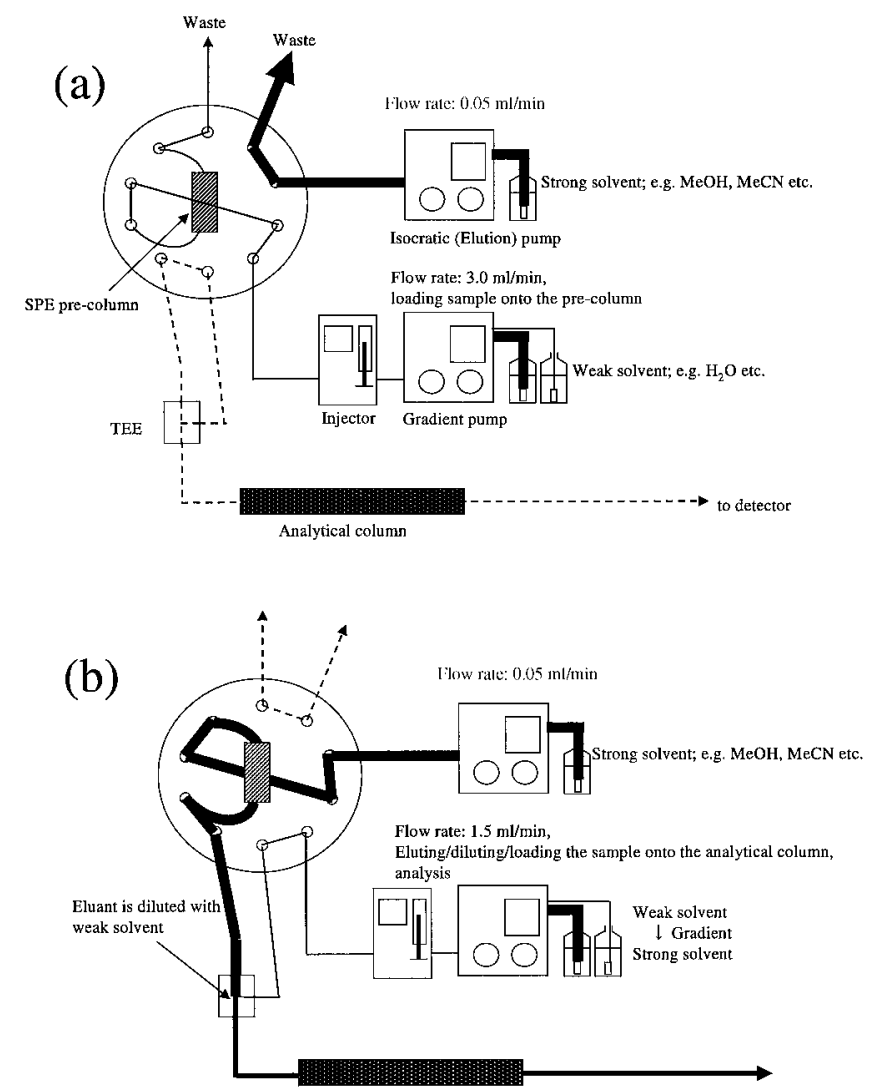

Fig. 1 Schematic diagram of the on-line SPE/ACD system. (a) Sample preparation process. (b) Sample eluting/diluting/analysis process.

from Wako Chemicals (Osaka, Japan). Carpropamid, thiodicarb were purchased from Kanto Chemicals (Tokyo, Japan). Asulam, azoxystrobin were obtained from Hayashi Pure Chemical (Osaka, Japan). Benomyl was obtained from Riedelde Hën AG (Seeiz, Germany). The crystals were dissolved in HPLC-grade methanol at $1 \mathrm{mg} / \mathrm{mL}$ each to make stock solutions. The standard solutions were stored at $-20^{\circ} \mathrm{C}$ in the dark. Methanol and water (HPLC grade) were from Kanto Chemicals. Leucin enkephalin was from Sigma-Aldrich (St. Louis, MO, USA). Other chemicals were from Wako Chemicals.

River water samples were collected from the dam side of Naka-River in Ibaraki Prefecture as a representative "clean" water site that contains relatively few interfering compounds, and the Takahama-Canal in the bay area of Tokyo city as a representative "dirty" water site that contains relatively high levels of interfering compounds. Surface-water samples were collected using a polyethylene beaker and stocked in capped $1000 \mathrm{~mL}$ polyethylene bottles. The samples were stored at $4^{\circ} \mathrm{C}$ for between 3 days and 2 weeks before analysis.

Standard mixtures were prepared by mixing the stock solutions with $50 \%$ methanol to obtain final concentrations of $10 \times 10^{-3} \mathrm{mg} / \mathrm{mL}$ each.

\section{Description of Method}

On line sample preparation procedure

A schematic diagram of sample loading onto the SPE precolumn is shown in Fig. 1(a). The gradient pump sends a weak solvent (e.g. $\mathrm{H}_{2} \mathrm{O}$ or initial mobile phase) at a flow rate of $3.0 \mathrm{~mL} / \mathrm{min}$,
Table 1 Time programs of eluent composition rate, flow rate and switching valve events

\begin{tabular}{|c|c|c|c|c|c|c|}
\hline $\begin{array}{c}\text { Time/ } \\
\text { min }\end{array}$ & $\% \mathrm{~A}$ & $\% \mathrm{~B}$ & $\% \mathrm{C}$ & 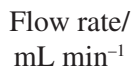 & Curve & Event \\
\hline 0.0 & 95 & 0 & 5 & 1.5 & 1 & \\
\hline 0.0 & & & & & & Switch 1 Off \\
\hline 0.1 & 95 & 0 & 5 & 3.0 & 6 & \\
\hline 1.0 & 95 & 0 & 5 & 3.0 & 6 & \\
\hline 1.1 & 95 & 0 & 5 & 1.5 & 6 & \\
\hline 1.5 & & & & & & Switch 1 On \\
\hline 20.0 & 95 & 0 & 5 & 1.5 & 6 & \\
\hline 22.0 & 60 & 30 & 5 & 1.5 & 6 & \\
\hline 32.0 & 0 & 95 & 5 & 1.5 & 6 & \\
\hline 37.0 & 95 & 0 & 5 & 1.5 & 11 & \\
\hline 41.5 & & & & & & Switch 1 Off \\
\hline
\end{tabular}

Table 2 Time programs of eluent composition

\begin{tabular}{crrcc}
\hline Time/min & $\% \mathrm{~A}$ & $\% \mathrm{~B}$ & $\% \mathrm{C}$ & Curve \\
\hline 0.0 & 95 & 0 & 5 & 1 \\
2.0 & 60 & 30 & 5 & 6 \\
12.0 & 0 & 95 & 5 & 6 \\
17.0 & 95 & 0 & 5 & 11 \\
\hline
\end{tabular}

Flow rate: $1.0 \mathrm{~mL} / \mathrm{min}$.

which carries the sample from the sample loop to the precolumn. The use of a weak solvent in this step increases the injection volume and flushes away the interfering sample matrix.

Figure 1(b) shows a diagram of sample loading onto the analytical column. A strong solvent (e.g. methanol or acetonitrile) delivered by the isocratic pump at a flow rate of $0.05 \mathrm{~mL} / \mathrm{min}$ elutes the whole sample remaining in the precolumn. The eluate is diluted at the TEE with the weak solvent from the gradient pump at a flow rate of $1.5 \mathrm{~mL} / \mathrm{min}$. Thus, the eluate is diluted 31 fold with the weak solvent. The dilution factor depends on the ratio between the flow rate of the isocratic pump and that of the gradient pump. Consequently, low hydrophobic compounds eluted with the strong solvent can be easily retained on the analytical column.

\section{Mass spectrometry}

The electrospray positive mode was used for MS detection. The electrospray source conditions were: capillary voltage, $3000 \mathrm{~V}$; sample cone, $50 \mathrm{~V}$; source temperature, $120^{\circ} \mathrm{C}$; cone gas, $50 \mathrm{~L} / \mathrm{h}$; desolvation gas temperature, $300^{\circ} \mathrm{C}$; and desolvation gas flow, $1200 \mathrm{~L} / \mathrm{h}$.

A leucine enkephalin $\left(\mathrm{C}_{28} \mathrm{H}_{37} \mathrm{~N}_{5} \mathrm{O}_{7}\right)$ solution $\left(1.0 \times 10^{-3}\right.$ $\mathrm{mg} / \mathrm{mL}$ ) was sprayed at a flow rate of $0.005 \mathrm{~mL} / \mathrm{min}$ from a secondary sprayer during the analysis, and its spectra were collected separately from the sample spectra. The leucine enkephalin protonated peak at $\mathrm{m} / \mathrm{z}, 556.2771$ was used as an internal reference to enable accurate mass ( $3 \mathrm{ppm} ; \pm 1.5 \mathrm{mDa}$ at $\mathrm{m} / \mathrm{z}$ 500) determination.

For all quantitative analyses, the peak-area responses were calculated from the reconstructed mass chromatogram within the range of each protonated ion, $\pm 0.05 \mathrm{Da}$.

W mode (approximately FWHM 10000) scan responses were collected from $\mathrm{m} / \mathrm{z}, 150$ to 1000 at a rate of $0.2 \mathrm{~s} / \mathrm{scan}$. The dynamic range enhancement (DRE) function was used. For the purpose of screening or highly sensitive methods, the $\mathrm{V}$ mode (approximately FWHM 5000) and a scan rate of 1 s/scan can 
Table 3 LOD and chemical properties for twenty-one pesticides

\begin{tabular}{|c|c|c|c|c|c|}
\hline & $\begin{array}{l}\text { Compound } \\
\text { name }\end{array}$ & Formula & $\begin{array}{l}\text { Exact mass of } \\
{[\mathrm{M}+\mathrm{H}]^{+}(\mathrm{m} / z)}\end{array}$ & $\log P_{\mathrm{ow}}^{\mathrm{a}}$ & $\begin{array}{l}\text { LOD, } \\
\text { ppb }\end{array}$ \\
\hline 1 & Asulam & $\mathrm{C}_{8} \mathrm{H}_{10} \mathrm{~N}_{2} \mathrm{O}_{4} \mathrm{~S}$ & 231.0439 & -0.27 & 1.2 \\
\hline 2 & Azoxystrobin & $\mathrm{C}_{22} \mathrm{H}_{17} \mathrm{~N}_{3} \mathrm{O}_{5}$ & 404.1246 & 2.5 & 0.010 \\
\hline 3 & Benfuracarb & $\mathrm{C}_{20} \mathrm{H}_{30} \mathrm{~N}_{2} \mathrm{O}_{5} \mathrm{~S}$ & 411.1953 & 4.22 & 0.014 \\
\hline 4 & Benomyl & $\mathrm{C}_{14} \mathrm{H}_{18} \mathrm{~N}_{4} \mathrm{O}_{3}$ & 291.1457 & 1.37 & 0.50 \\
\hline 5 & Bensulfuron-methyl & $\mathrm{C}_{16} \mathrm{H}_{18} \mathrm{~N}_{4} \mathrm{O}_{7} \mathrm{~S}$ & 411.0974 & 2.45 & 0.010 \\
\hline 6 & Bensulide & $\mathrm{C}_{14} \mathrm{H}_{24} \mathrm{NO}_{4} \mathrm{PS}_{3}$ & 398.0683 & 4.2 & 0.030 \\
\hline 7 & Carbaryl & $\mathrm{C}_{12} \mathrm{H}_{11} \mathrm{NO}_{2}$ & 202.0868 & 1.85 & 0.27 \\
\hline 8 & Carbofuran & $\mathrm{C}_{12} \mathrm{H}_{15} \mathrm{NO}_{3}$ & 222.1130 & 1.52 & 0.013 \\
\hline 9 & Carpropamid & $\mathrm{C}_{15} \mathrm{H}_{18} \mathrm{Cl}_{3} \mathrm{NO}$ & 334.0532 & 4.23 & 0.20 \\
\hline 10 & Daimuron & $\mathrm{C}_{17} \mathrm{H}_{20} \mathrm{~N}_{2} \mathrm{O}$ & 269.1654 & 2.7 & 0.0034 \\
\hline 11 & Diuron & $\mathrm{C}_{9} \mathrm{H}_{10} \mathrm{Cl}_{2} \mathrm{~N}_{2} \mathrm{O}$ & 233.0248 & 2.85 & 0.042 \\
\hline 12 & Flazasulfuron & $\mathrm{C}_{13} \mathrm{H}_{12} \mathrm{~F}_{3} \mathrm{~N}_{5} \mathrm{O}_{5} \mathrm{~S}$ & 408.0589 & -0.06 & 0.029 \\
\hline 13 & Halosulfuron-methyl & $\mathrm{C}_{13} \mathrm{H}_{15} \mathrm{ClN}_{6} \mathrm{O}_{7} \mathrm{~S}$ & 435.0489 & -0.00186 & 0.030 \\
\hline 14 & MBC (Carbendazim) & $\mathrm{C}_{9} \mathrm{H}_{9} \mathrm{~N}_{3} \mathrm{O}_{2}$ & 192.0773 & 1.38 & 0.017 \\
\hline 15 & Methomyl & $\mathrm{C}_{5} \mathrm{H}_{10} \mathrm{~N}_{2} \mathrm{O}_{2} \mathrm{~S}$ & 163.0535 & 0.093 & 0.18 \\
\hline 16 & Oxine-copper & $\mathrm{C}_{9} \mathrm{H}_{6} \mathrm{NO}$ & 145.0527 & 2.46 & 3.3 \\
\hline 17 & Siduron & $\mathrm{C}_{14} \mathrm{H}_{20} \mathrm{~N}_{2} \mathrm{O}$ & 233.1576 & 3.8 & 0.050 \\
\hline 18 & Thiodicarb & $\mathrm{C}_{10} \mathrm{H}_{18} \mathrm{~N}_{4} \mathrm{O}_{4} \mathrm{~S}_{3}$ & 355.0568 & 1.62 & 0.019 \\
\hline 19 & Thiophanate-methyl & $\mathrm{C}_{12} \mathrm{H}_{14} \mathrm{~N}_{4} \mathrm{~S}_{2} \mathrm{O}_{4}$ & 343.0534 & 1.50 & 0.075 \\
\hline 20 & Thiram & $\mathrm{C}_{6} \mathrm{H}_{12} \mathrm{~N}_{2} \mathrm{~S}_{4}$ & 240.9961 & 1.73 & 0.18 \\
\hline 21 & Tricyclazole & $\mathrm{C}_{9} \mathrm{H}_{7} \mathrm{~N}_{3} \mathrm{~S}$ & 190.0439 & 1.4 & 0.052 \\
\hline
\end{tabular}

a. The e-Pesticide Manual 12th ed., British Crop Protection Council, 2001.

also be adopted as alternative conditions, yielding about a 10fold sensitivity.

\section{HPLC}

Solvent A was $\mathrm{H}_{2} \mathrm{O}$, solvent B was acetonitrile and solvent $\mathrm{C}$ was $2 \%$ formic acid. Time programs of the eluent composition, the flow rate and the switching valve events are given in Table 1. Using methanol instead of acetonitrile increased the signal intensity, but it caused a high pressure of more than 3000 psi during the gradient at a higher flow rate of $1.0 \mathrm{~mL} / \mathrm{min}$, and interrupted the analysis. In order to avoid this high pressure, a shorter or wider bore analysis column was adopted for the use of methanol. The column temperature was set at $50^{\circ} \mathrm{C}$.

At the initial condition, the valve position is at the "sample preparation" position and the precolumn is equilibrated with the weak mobile phase at a flow rate of $1.5 \mathrm{~mL} / \mathrm{min}$. After sample injection the flow rate is increased to $3.0 \mathrm{~mL} / \mathrm{min}$ within 0.1 min, and the condition is held until the 1.0 min mark. In this process, the sample is loaded onto the precolumn which is successively washed with the aqueous mobile phase to remove the interfering matrix. The flow rate is decreased to $1.5 \mathrm{~mL} / \mathrm{min}$ at $1.1 \mathrm{~min}$, and this process should be done during the period from 0.2 to $0.5 \mathrm{~min}$ prior to the valve position changing, because switching the flow line at a high flow rate would cause the pressure to exceed the column capacity. Valve switching to the "analysis position" at $1.5 \mathrm{~min}$ avoids high pressure. While these conditions are kept until the 20.0 min mark, the sample is eluted from the precolumn inside out, is diluted at the TEE with the mobile phase, and is finally loaded onto the analytical column. The compounds are eluted from the analytical column while the gradient starts at $20.0 \mathrm{~min}$ and ends at the $37.0 \mathrm{~min}$ mark. The analytical column is equilibrated with the weak mobile phase from $37.0 \mathrm{~min}$ to $41.5 \mathrm{~min}$. Finally, the valve is returned to the "sample preparation" position at the 41.5 min mark.

In order to evaluate the advantages of the proposed SPE/ACD system, the following LC conditions were used. The analytical column was an Atlantis dC18 $150 \times 4.6 \mathrm{~mm}$ i.d. $5 \mu$, the column temperature was $50^{\circ} \mathrm{C}$, the flow rate was $1.0 \mathrm{~mL} / \mathrm{min}$ and the injection volume was $500 \mu \mathrm{L}$, which is approximately a 20 -fold larger volume than that of typical chromatography. Solvent A was $\mathrm{H}_{2} \mathrm{O}$, solvent $\mathrm{B}$ was acetonitrile and solvent $\mathrm{C}$ was $2 \%$ formic acid. The time course of the gradient is given in Table 2.

\section{Application to the LC method}

A LC/oa-TOF MS method was established to confirm the applicability of the present on-line SPE/ACD system to the LC method. Twenty-one pesticides having a wide variety of octanol-water partition coefficients $\left(\log P_{\text {ow }}\right)$ were chosen as target compounds to assess the ability of simultaneous analysis (Table 3). River-water samples were chosen as representative of real samples.

Figure 2 shows typical TIC chromatograms of a standards mixture (100 ppb) added to river water.

\section{Maximum injection volume}

To estimate the maximum injection volume, the linearity was calculated. River water spiked with standard compounds (100 ppb each) of volumes between $0.025 \mathrm{~mL}$ and $1.000 \mathrm{~mL}$ was injected. Good linearities with regression coefficients greater than 0.999 were observed in the injection volumes between 0.025 to $0.500 \mathrm{~mL}$, except for benomyl (0.986; Fig. 3(a)). Because benomyl was not completely eluted using only acetonitrile, ${ }^{1}$ and was easily decomposed to make methyl benzimidazol-2-ylcarbamate (MBC), a convex curve was obtained in the range between $0.100 \mathrm{~mL}$ and $1.000 \mathrm{~mL}$ (Fig. 3(b)). Because the standard solution was also pretreated in the same manner, a variation of the pretreatment was negligible. This injection volume was 20-fold larger than the typical injection volumes (around $0.025 \mathrm{~mL}$ ) for a $150 \times 4.6 \mathrm{~mm}$ i.d. column. Although the maximum injection volume for this system configuration was $2 \mathrm{~mL}$, the injection volume giving the best results was in the range between 0.025 and $0.500 \mathrm{~mL}$.

Every calibration curve was saturated at $1.000 \mathrm{~mL}$ in both UV and MS response, while each chromatographic peak shape was 


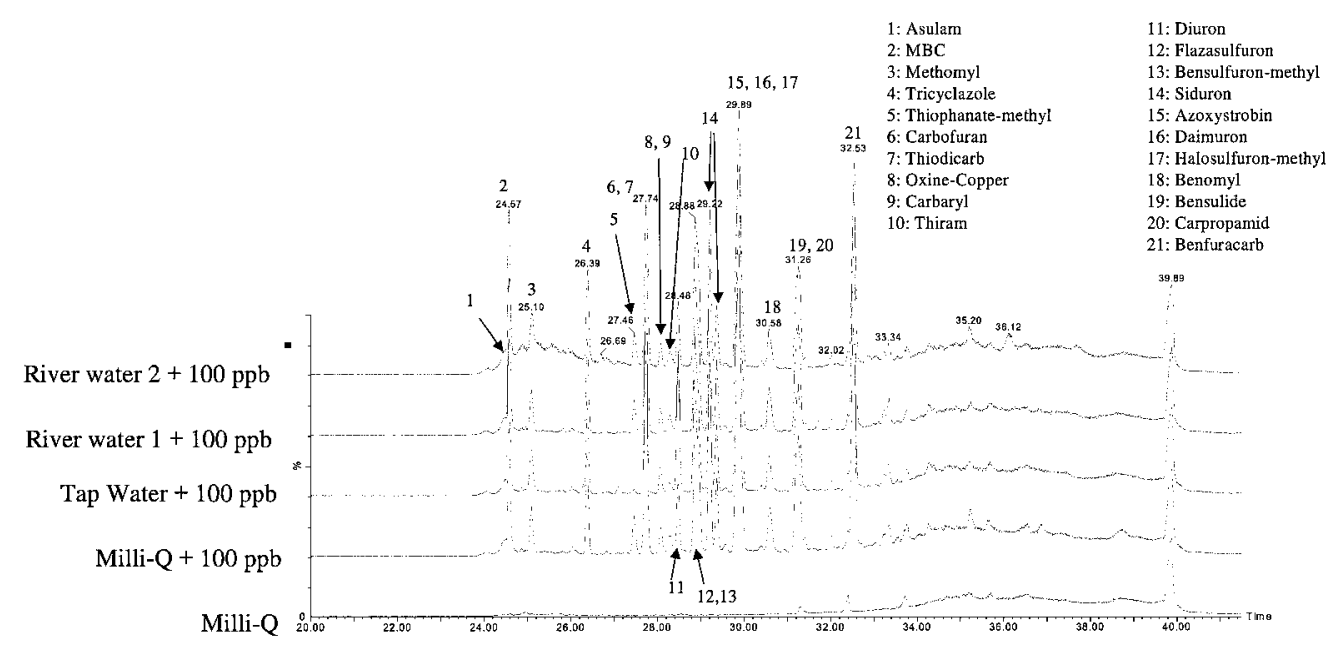

Fig. 2 Typical chromatogram of standards mixture (100 ppb) added to river water.

(a)

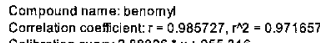

Conrelation coeffcient: $=0.985727, \mathrm{r}_{2}-0.97$
Calibration curve: $2.88396 * x+255.316$

Rasponse uppe: Exeranal Std, Area
Cunve tpe: Lirear, Origin: Exclude, Weighting: Nul, Axis tans: None

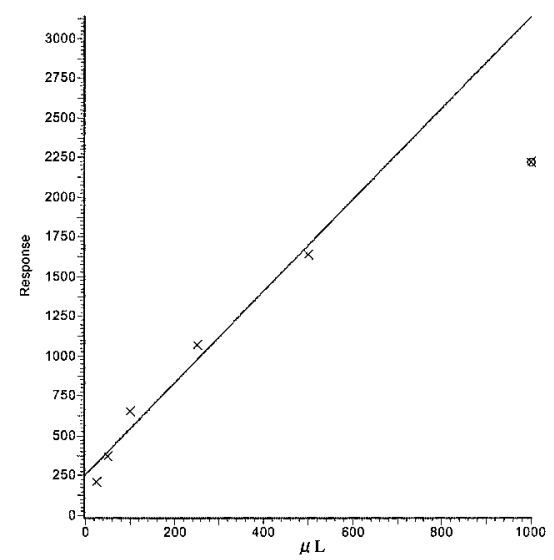

(b)
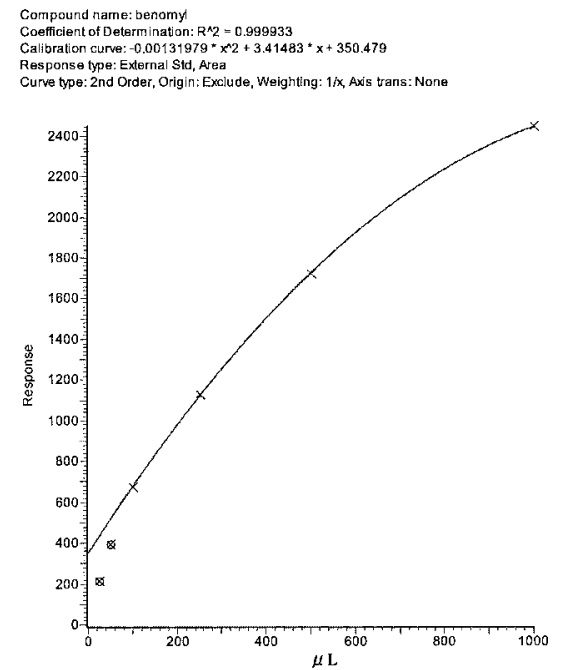

Fig. 3 Calibration curve of benomyl. (a) Coefficient factor, 0.986, (b) convex curve.

symmetric. Therefore, this saturation was due to mass-overload caused by injecting more matrix than the capacity of the precolumn. In order to obtain a higher concentration factor, a larger size precolumn can be chosen.

\section{Results and Discussion}

\section{Validation test and application to the real sample}

To confirm the applicability of the present on-line SPE/ACD system to real samples, some river water samples were analyzed. Validation tests were carried out using river water samples to which pesticides were added in a concentration range from 1 and $1000 \mathrm{ppb}$.

The linear range of this MS method was obtained in the concentration range from 1 and $100 \mathrm{ppb}$ with the linearity greater than 0.999 by the external calibration mode. The MS responses were saturated more than $100 \mathrm{ppb}$, while the UV responses were not saturated until $1000 \mathrm{ppb}$. Because the injection volume was 20-times as much as that of typical chromatography, this concentration range corresponds to the range from $20 \mathrm{ppb}$ to $2000 \mathrm{ppb}$ at an injection volume of 0.025 $\mathrm{mL}$. At a concentration of $100 \mathrm{ppb}$, the isotope abundance ratio was larger than that expected. Thus, this saturation of MS response was due to the ion counting system.

The detection limits were estimated by calculating from a 0.05 Da mass chromatogram of $1 \mathrm{ppb}$ standards at a signal-to-noise ratio of 3. The detection limits were $0.0034 \mathrm{ppb}$ for daimuron to $3.3 \mathrm{ppb}$ for oxine-copper, and almost all were at the sub-ppb level, except for asulam and oxine-copper (Table 3). The recoveries from river water were determined by comparing the responses of $100 \mathrm{ppb}$-spiked samples with those of $100 \mathrm{ppb}$ standard solutions dissolved in distilled water.

The recoveries were in the range from $67 \%$ (asulam in the "dirty" sample) to $126 \%$ (benfuracarb in the "clean" sample). The mean recovery was $83 \%$, except for thiram, which was assumed to be decomposed in the sample-preparation procedure.

The reproducibility $(\mathrm{CV} \%)$, estimated by comparing riverwater samples spiked with $100 \mathrm{ppb}$ standards $(n=4)$, were $1.1 \%$ for flazasulfuron in the "dirty" water and $11 \%$ for thiophanate-methyl. The mean reproducibility was 5.6\%.

Figure 4 compares the recoveries obtained with (a) and without (b) this proposed system. The variation of the recoveries obtained by not using the proposed system were obviously larger $(70-240 \%$; mean, $115 \%$; CV\%, 31\%) in the "clean" sample and smaller (24-124\%; mean, 62\%; CV\%, 

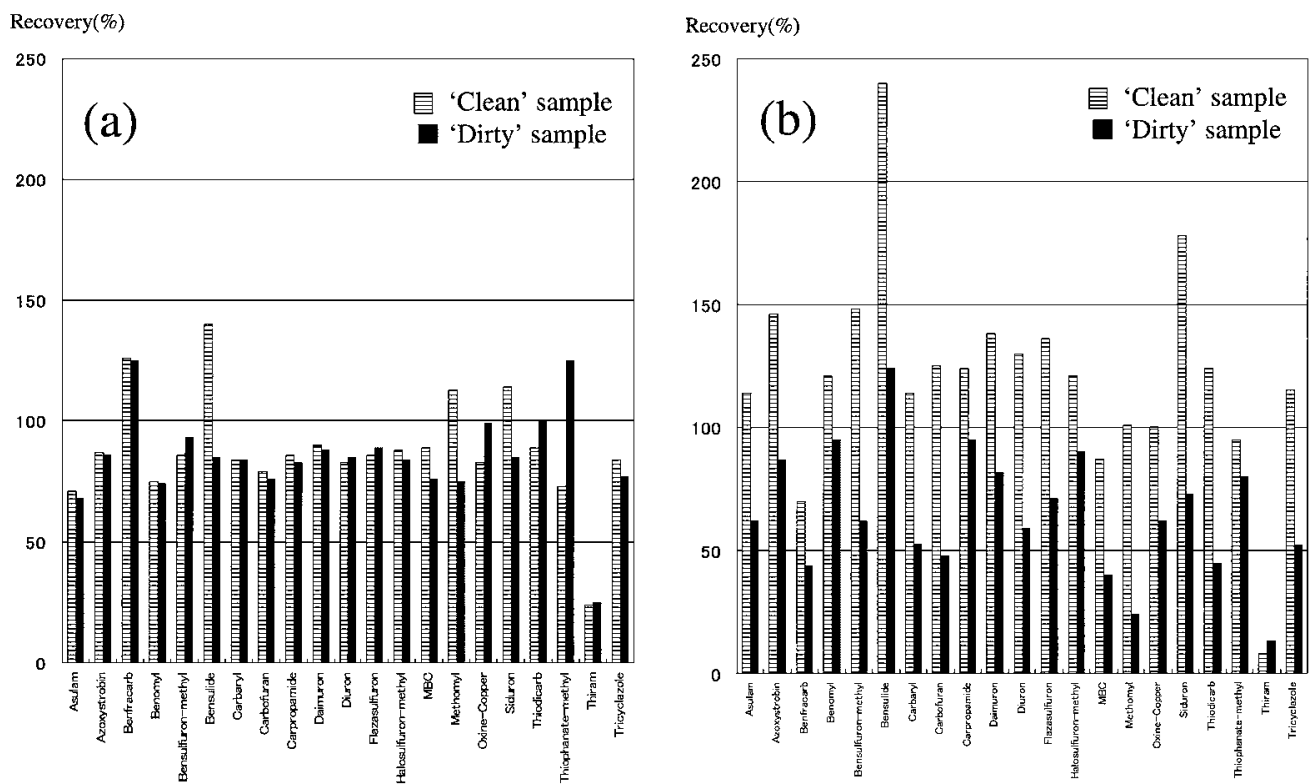

Fig. 4 Comparison of recoveries: (a) by using the proposed system, (b) by not using the proposed system. Thirum may be decomposed in a sample solution.
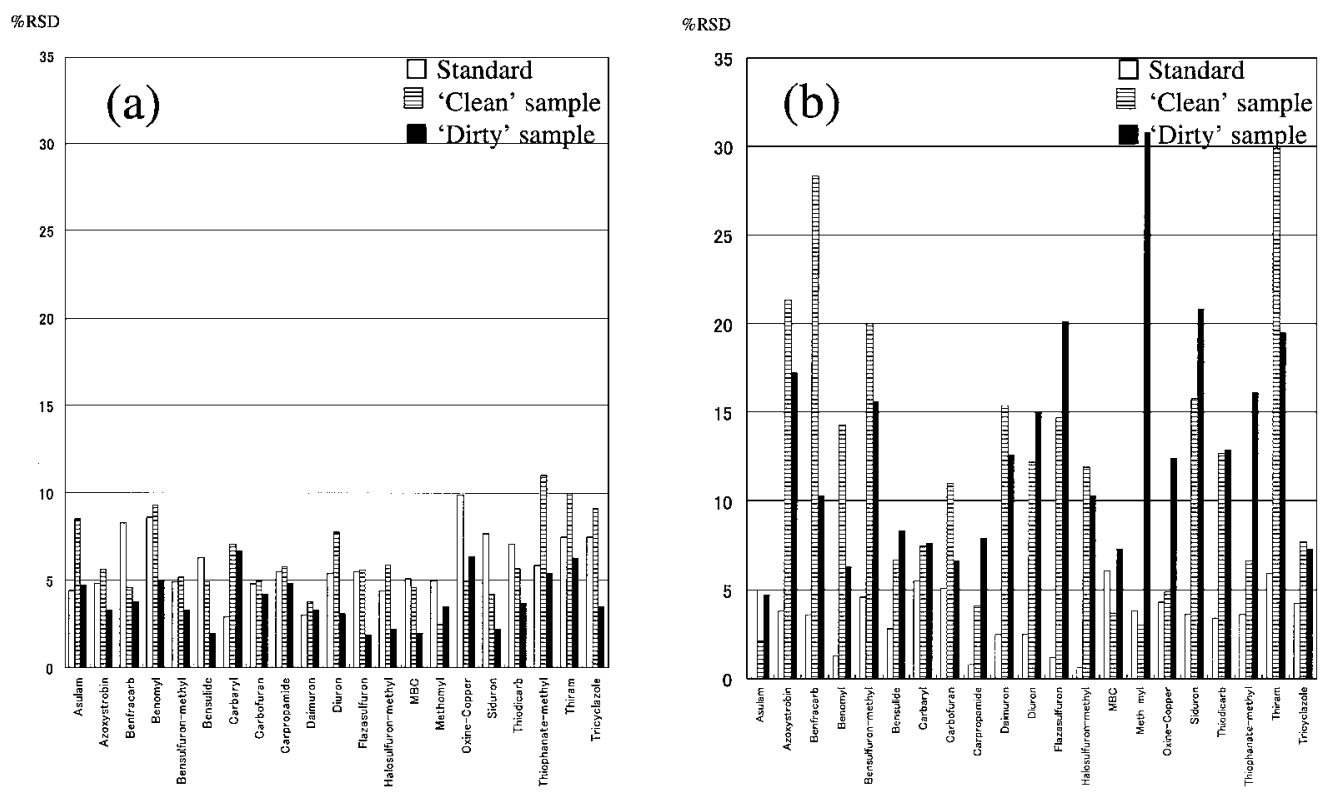

Fig. 5 Comparison of reproducibility; (a) by using the proposed system, (b) by not using the proposed system.

$38 \%$ ) in the "dirty" sample than that obtained by using the proposed system.

Figure 5 compares the reproducibilities obtained with (a) and without (b) the proposed system. Also, the variation of the reproducibility obtained by not using the proposed system was obviously larger $(2.1-31 \%$; mean, $12 \%)$.

Thus, the on-line SPE/ACD/LC/oa-TOF MS method was successfully applied to the simultaneous determination of pesticides in river water. This demonstrates that the present system has sufficient capability to survey unexpected contaminants in environmental samples.

Most studies of work to detect environmental contaminants with LC/MS use a tandem quadrupole MS/MS detector in a selected reaction monitoring (SRM) mode. The SRM mode records only the selected known target ions, but not the whole spectra. Also, the appropriate monitoring time (dwell time) in the SRM mode is in the range between 10 to $100 \mathrm{~ms}$ for most instruments. This is not sufficient to record whole ions of potential contaminants. Thus, analysts should select the target compounds to be monitored before analysis. Therefore, unexpected contaminants may not be recorded when a tandem quadrupole MS/MS is used.

On the other hand, the oa-TOF MS records highly resolved and highly sensitive whole scan data, contributing to the separation of a complex sample matrix and to an accurate determination of the mass/elemental composition. Analysts can elicit information about unexpected contaminants by reprocessing the spectra acquired by oa-TOF MS. 
This proposed on-line SPE/ACD system can be easily installed in a conventional HPLC system, because it does not need to change any tubing between the pump and the injector. It requires only putting the on-line SPE/ACD system between an injector and an analytical column. This feature can help to extend applications of the proposed system.

\section{Conclusion}

A new on-line sample preparation system for LC/TOF-MS is presented.

The on-line SPE/ACD/LC/oa-TOF MS system can be used to simultaneously determine pesticides that have a wide variety of hydrophobic properties and that exist at sub ppb levels in river water. Good linearities, recoveries and sufficiently low detection limits were obtained. This system could be useful for providing a profile of environmental samples that contain a wide variety of unexpected or unknown chemical contaminants.

\section{References}

1. N. Makihata, T. Kawamoto, and K. Teranishi, Anal. Sci., 2003, 19, 543.

2. F. Bruno, R. Curini, A. D. Corcia, M. Nazzari, and Samperi, Rapid Commun. Mass Spectrom., 2001, 15, 1391.

3. A. Motoyama, A. Suzuki, O. Shirota, and R. Namba, Rapid Commun. Mass Spectrom., 1999, 13, 2204.

4. A. C. Hogenboom, W. M. A. Niessen, D. Little, and U. A. Th. Brinkman, Rapid Commun. Mass Spectrom., 1999, 13, 125.

5. Y. Yoshida, Y. Ishii, Y. Ito, M. Uebori, K. Kawata, M. Takino, A. Hasegawa, H. Fukui, M. Murakami, H. Moriwaki, A. Yasuhara, J. Yonekubo, and S. Suzuki, "Waste Management in Japan", ed. H. Itoh, 2004, 109.

6. S. Laks, A. Pelander, E. Vuori, E. Ali-Tolppa, E. Sippola, and I. Ojanpera, Anal. Chem., 2004, 76, 7375.

7. I. Ferrer, M. Mezcua, M. J. Gomez, E. M. Thurman, A. Aguera, M. D. Hernando, and A. R. Fernandez-Alba, Rapid Commun. Mass Spectrom., 2004, 18, 443.

8. P. Kebarle and L. Tang, Anal. Chem., 1993, 65, 972A.

9. J. Henion, E. Brewer, and G. Rule, Anal. Chem., 1998, 70,
650A.

10. I. Fu, E. J. Woolf, and B. K. Matuszewski, J. Pharm. Biomed. Anal., 1998, 18, 347.

11. B. K. Matuszewski, M. L. Constanzer, and C. M. ChavezEng, Anal. Chem., 1998, 70, 882.

12. G. Balizs, J. Chromatogr. B, 1999, 727, 167.

13. J. Ding and U. D. Neue, Rapid Commun. Mass Spectrom., 1999, 13, 2151.

14. T. L. Constanopoulos, G. S. Jackson, and C. G. Enke, J. Am. Mass Spectrom., 1999, 10, 625.

15. E. Dijikman, D. Mooibroek, R. Hoogerbrugge, E. Hogendoorn, J. V. Sancho, O. Pozo, and F. Hernández, J. Chromatogr. A, 2001, 926, 113.

16. C. Muller P. Schäfer, M. Störzel, S. Vogt, and W. Weinmann, J. Chromatogr. B, 2002, 73, 47.

17. S. Ito and K. Tsukada, J. Chromatogr. A, 2002, 943, 39.

18. J. J. Zheng, E. D. Lynch, and S. E. Unger, J. Pharm. Biomed. Anal., 2002, 28, 279.

19. H. Mei, Y. Hsieh, C. Nardo, X. Xu, S. Wang, K. Ng, and W. A. Korfmacher, Rapid Commun. Mass Spectrom., 2003, 17, 97.

20. M. Stuber and T. Reemtsma, Anal. Bioanal. Chem., 2004, 378, 910.

21. European directive 2002/657/EC, Official Journal of the European Communities, 2002, L221/8-L221/36 (http://europa.eu.int/eur-lex/pri/en/oj/dat/2002/1_221/1_ 22120020817en00080036.pdf).

22. FDA Center for Veterinary Medicine, Guidance for Industry 118, 2003 (http://www.fda.gov/cvm/guidance/guide118.pdf).

23. K. F. Blom, J. Comb. Chem., 2004, 4, 295.

24. D. C. Cole, N. Pagano, M. F. Kelly, and J. Ellingboe, J. Comb. Chem., 2004, 6, 78.

25. A. C. Hogenboom, W. M. A. Niessn, and U. A. Th. Brinkman, J. Chromatogr. A, 1998, 794, 201.

26. A. C. Hogenboom, W. M. A. Niessn, and U. A. Th. Brinkman, J. Chromatogr. A, 1999, 841, 33.

27. A. C. Hogenboom, M. P. Hofman, D. A. Jolly, W. M. A. Niessn, and U. A. Th. Brinkman, J. Chromatogr. A, 2000, $885,377$.

28. A. C. Hogenboom, M. P. Hofman, S. J. Kok, W. M. A. Niessen, and U. A. Th. Brinkman, J. Chromatogr. A, 2000, 892,379 . 